See Article page 838 .

\section{Commentary: Maximum surgery through minimal incisions}

\author{
Richard Lazzaro, MD, and Byron Patton, MD
}

Since the first successful pneumonectomy for management of locally advanced lung cancer, performed by Evarts Graham on April 5, 1933, the surgical approach to lung cancer has evolved. Today, the standard of care for early-stage lung cancer is lobectomy with appropriate mediastinal lymph node evaluation. However, as stated by P. H. Jones in 1958, when "standard lobectomy cannot meet the minimum pathological requirements for extirpation of this lesion, and pneumonectomy may be precluded by the patient's age or poor cardiovascular function. .... It is under those circumstances that the operation of lobectomy, with sleeve resection of the main bronchus, has its place-since by this means removal of all tumour bearing tissue and lymph nodes may be carried out with resection of less than the entire lung." 1 Nevertheless, when the tumor is central and standard lobectomy is unable to result in an adequate oncologic procedure, ie, negative margins, then pneumonectomy has historically been and currently remains the most commonly performed approach. ${ }^{2}$

Since the first sleeve resection for cancer had been first performed by Allison in 1952 (reported in Jones ${ }^{1}$ ), it remains vital that the comparison of different surgical approaches should include 3 main questions, as proposed by Firman. "Is the operative mortality low ... is the functional result as good, and ... does sleeve lobectomy achieve adequate tumor clearance and equivalent tumor free survival?", $3 \mathrm{Tong}^{4}$ noted that multiple studies comparing the outcomes of sleeve lobectomy with pneumonectomy revealed that disease-free survival, overall survival, and postoperative quality of life all favor sleeve lobectomy, ${ }^{5-9}$ albeit with an increased risk of

\footnotetext{
From the Department of Cardiothoracic Surgery, Lenox Hill Hospital, New York, NY. Disclosures: Authors have nothing to disclose with regard to commercial support.

Received for publication Nov 11, 2019; accepted for publication Nov 12, 2019; available ahead of print Nov 30, 2019.

Address for reprints: Richard Lazzaro, MD, Division of Thoracic Surgery, Robotic Thoracic Surgery, Lenox Hill Hospital, 130 East 77th St, New York, NY 10075 (E-mail: rlazzaro@northwell.edu).

J Thorac Cardiovasc Surg 2020;160:849-50 0022-5223/ $\$ 36.00$

Copyright (c) 2019 by The American Association for Thoracic Surgery https://doi.org/10.1016/j.jtcvs.2019.11.055
}

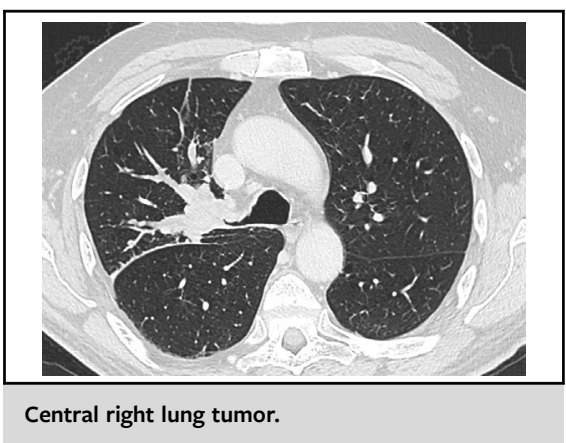

CENTRAL MESSAGE

Robotic sleeve lobectomy is a safe and feasible procedure. Training programs and mentorship opportunities will further the safe adoption of maximal surgery through minimal incisions.

postoperative pulmonary complications (atelectasis and pneumonia). ${ }^{5}$ Previous reports have also demonstrated that sleeve lobectomy does not compromise survival when compared with pneumonectomy for patients with N1 nodal disease. ${ }^{10}$

In this issue of the Journal, Qiu and colleagues ${ }^{11}$ report on the outcomes of a propensity score-weighted comparison of robotic-assisted sleeve lobectomy with thoracoscopic and open surgery for centrally located non-small cell lung cancer, detailing perhaps the largest series of sleeve lobectomy. The authors demonstrated that robotic sleeve lobectomy has a similar oncologic prognosis when compared with video-assisted thoracoscopic surgery and open sleeve lobectomy and is a safe and feasible procedure. Detailed preoperative planning with radiographic review, including 3-dimensional computed tomography reconstructions, as well as bronchoscopic assessment of the tumor, are mandatory to attain negative bronchial margins. Mastery of surgical anatomy and the ability to safely create separation of central structures are essential to achieve negative margins and are often facilitated by complete lymphadenectomy. The creation of a tension-free bronchial anastomosis can be performed by multiple techniques, including interrupted, running, or a combination. These complex maneuvers are enhanced 
by robotic assistance and its increased degrees of freedom, stereoscopic vision, magnification, and scaled motion.

The consistent ability to overcome absolute or relative contraindications to video-assisted thoracoscopic surgery anatomic lung resections such as pneumonectomy or sleeve, while maintaining sound surgical oncologic principles, has now been shown by multiple authors on multiple continents. The added benefit of minimally invasive resection in regards to the increased likelihood of receiving and completing adjuvant therapy may play a pivotal role in the multimodal approach to lung cancer in this group of patients who usually require thoracotomy. For myself, I follow the wisdom of Franz Torek, who reflected that Dr Willy Meyer (American Association for Thoracic Surgery founder and distinguished staff surgeon of the German Hospital, now the Lenox Hill Hospital) was an "ardent student of medical literature ... eager to grasp and accept anything that impressed him as being a valuable addition or improvement in surgical procedure." ${ }^{12,13}$ It remains important to further develop consistent training programs and mentorship to further the safe adoption of minimally invasive surgery to the complex central tumors of the chest in patients without limited cardiopulmonary reserve but especially in those otherwise considered inoperable if pneumonectomy is the only option. We should strive to perform maximal surgery through minimal incisions to mitigate surgical risk and optimize patient outcomes.

\section{References}

1. Jones PH. Lobectomy and bronchial anastomosis in the surgery of bronchial carcinoma. Ann R Coll Surg Engl. 1959;25:20.

2. Boffa DJ, Allen MS, Grab JD, Gaissert HA, Harpole DH, Wright CD. Data from the Society of Thoracic Surgeons general thoracic surgery database: the surgical management of primary lung tumors. J Thorac Cardiovasc Surg. 2008;135: 247-54.

3. Firmin RK, Azariades M, Lennox SC, Lincoln JC, Paneth M. Sleeve lobectomy for bronchial carcinoma. Ann Thorac Surg. 1983;35:442-9.

4. Tong BC. Less is more. J Thorac Cardiovasc Surg. 2017;153:196.

5. Pages PB, Mordant P, Renaud S, Brouchet L, Thomas PA, Dahan M, et al. Sleeve lobectomy may provide better outcomes than pneumonectomy for non-small cell lung cancer. A decade in a nationwide study. J Thorac Cardiovasc Surg. 2017; 153:184-95.

6. Ferguson MK, Lehman AG. Sleeve lobectomy or pneumonectomy: optimal management strategy using decision analysis techniques. Ann Thorac Surg. 2003;76: $1782-8$.

7. Ma Z, Dong A, Fan J, Cheng H. Does sleeve lobectomy concomitant with or without pulmonary artery reconstruction (double sleeve) have favorable results for non-small cell lung cancer compared with pneumonectomy? A meta-analysis. Eur J Cardiothorac Surg. 2007;32:20-8.

8. Shi W, Zhang W, Sun H, Shao Y. Sleeve lobectomy versus pneumonectomy for non-small cell lung cancer: a meta-analysis. World J Surg Oncol. 2012;10:265.

9. Balduyck B, Hendriks J, Lauwers P, Van Schil P. Quality of life after lung cancer surgery: a prospective pilot study comparing bronchial sleeve lobectomy with pneumonectomy. J Thorac Oncol. 2008;3:604-8.

10. Berry MF, Worni M, Wang X, Harpole DH, D'Amico TA, Onaitis MW. Sleeve lobectomy for non-small cell lung cancer with N1 nodal disease does not compromise survival. Ann Thorac Surg. 2014;97:230-5.

11. Qiu T, Zhao Y, Xuan Y, Qin Y, Niu Z, Shen Y, et al. Robotic sleeve lobectomy for centrally located non-small cell lung cancer: a propensity score weighted comparison with thoracoscopic and open surgery. J Thorac Cardiovasc Surg. 2020; 160:838-46.e2.

12. Torek F. Memoirs. Willy Meyer, M.D. 1858-1932. Ann Surg. 1933;97:156-8.

13. Scannell JG. Historical perspectives of the American Association for Thoracic Surgery. Willy Meyer (1858-1932). J Thorac Cardiovasc Surg. 1996;111: 1112 . 